\title{
Chilled margins in igneous rocks
}

\author{
Herbert E. Huppert ${ }^{1}$ and R. Stephen J. Sparks ${ }^{2}$ \\ 'Department of Applied Mathematics and Theoretical Physics, University of Cambridge, Silver Street, Cambridge CB39EW (U.K.) \\ ${ }^{2}$ Department of Earth Sciences, University of Cambridge, Downing Street, Cambridge CB2 $3 E Q$ (U.K.)
}

Received November 2, 1988; revised version accepted January 30, 1989

\begin{abstract}
When hot magma contacts cold solid rock, a chilled margin forms because the heat flux from the magma cannot balance the very large initial conductive flux in the rock. However, the conductive flux decreases with time and can eventually be exceeded by the heat flux from the magma. In these circumstances, the chilled margin begins to remelt and can even disappear. This process is modelled quantitatively for the case of a constant heat flux from the magma. The results are applied to the turbulent steady flow of komatiite magma in dykes and as lavas. The initial chilled margin with cold rock only survives for a few tens of seconds and so does not inhibit thermal erosion significantly. The theory can also be applied to magmatic intrusions where the heat flux varies with time. Results are presented for the remelting of a chilled margin formed at the roof of a basaltic sill. For sills with thicknesses from 10 to $1000 \mathrm{~m}$, the remelting of initial chilled margins from a few tens of centimetres to a few tens of metres is possible. Three kinds of contact are predicted at the margins of intrusions. First, contacts are developed where the chilled margin grows continually without any meltback. Second, meltback can occur, but does not completely redissolve the initial chilled margin. This causes an internal contact to form within the intrusion. Third, meltback is complete and the country rock can then be melted and assimilated. The marginal rocks of such intrusions need not be fine grained.
\end{abstract}

\section{Introduction}

The initial response of magma emplaced against cold surrounding rock is to form a fine-grained chilled margin. It is often supposed that thereafter solidification continues, with the thickness of the margin increasing with time and accompanied by a coarsening of grain size. In contrast, a number of recent investigations have inferred that magmas can melt their boundaries and in suitable circumstances assimilate surrounding rock [1-5]. These later processes would be inhibited or even prevented by the formation of a chilled margin.

This paper investigates the fluid dynamics and heat transfer involved in the formation of chilled margins. Although an initial chill must always form we show that it will not necessarily grow ad infinitum, but can melt back after reaching a maximum thickness and then disappear. In this paper we use the term "chilled margin" sensu lato to include not only glassy rocks but also completely crystalline marginal rocks to intrusions which, because of their finer grain size than the interior, are usually perceived as the consequence of rapid cooling.
We present quantitative analyses of two specific situations. First, we investigate the case of turbulent flow of magma in lavas and dykes. Second, we investigate the remelting of a chilled margin formed at the roof of a convecting basaltic sill. The general principals revealed by these analyses can be applied quantitatively to any kind of intrusive margin. The results of the analysis have implications for assimilation of country rock into magmas and for the geological and textural characteristics of intrusive contacts.

\section{Theory}

We consider the heat transfer between a hot fluid at initial temperature $T_{\infty}$ and a cold solid at initial temperature $T_{0}$ along a planar boundary. There are a large number of different dynamical situations at such boundaries which depend on the orientation of the contact, the melting temperature of the solid, $T_{\mathrm{m}}$, the solidification temperature of the fluid, $T_{\mathrm{f}}$, and the physical properties of melt and fluid such as density, viscosity and thermal conductivity. A number of these situations have 
been investigated from a fluid dynamical point of view [4-8]. However, in this analysis we are first concerned with the initial response on contact of the fluid.

Huppert [9] has investigated several different cases for which the response depends in part on whether the initial solid has a higher or lower melting temperature than the fluid. In the geological context considered here, we are concerned only with the evolution of a solid chill formed from the magma and not with melting of the country rock behind the initial contact, which may be of quite different composition. Thus the relevant case for Huppert's study is that for which the compositions and hence transition temperatures for solid and liquid are the same, that is where $T_{\mathrm{m}}=T_{\mathrm{f}}$. A practical approximation for the effective melting temperature of many igneous rocks is neither the liquidus nor the solidus, but the temperature at which there is a transition from a partially molten solid to a crystal-rich magma. Observations $[10,11]$ indicate that the transition occurs over a rather narrow temperature interval with typical melt fractions of $35-45 \%$. In detail there may be subtle differences between the effective melting and solidification temperatures of the same magma due to kinetic reasons, but it is unlikely that these differences can be easily predicted or incorporated into modelling.

The heat transfer, $H$, will be some function of $\left(T_{\infty}-T_{\mathrm{f}}\right)$, which can be expressed as:

$H=f\left(T_{\infty}-T_{\mathrm{f}}\right)$.

For example, in a turbulent flow the function $f$ will be dependent on the Reynolds and Prandtl numbers. In a thermally convecting layer, the function will depend principally on the Rayleigh number and the temperature difference across the convecting chamber.

The finite heat flux, $H$, into the interface from the hot fluid occurs simultaneously with a large (initially infinite) conductive heat flux, $F$, in the solid. These fluxes can only be balanced by the latent heat released due to solidification of the fluid. As the conductive heat flux in the solid must initially exceed any heat flux from the fluid, the formation of a chilled margin must be the first response. As time proceeds, however, $F$ decreases monotonically as the conductive temperature profile relaxes. In the simple case in which $H$ remains

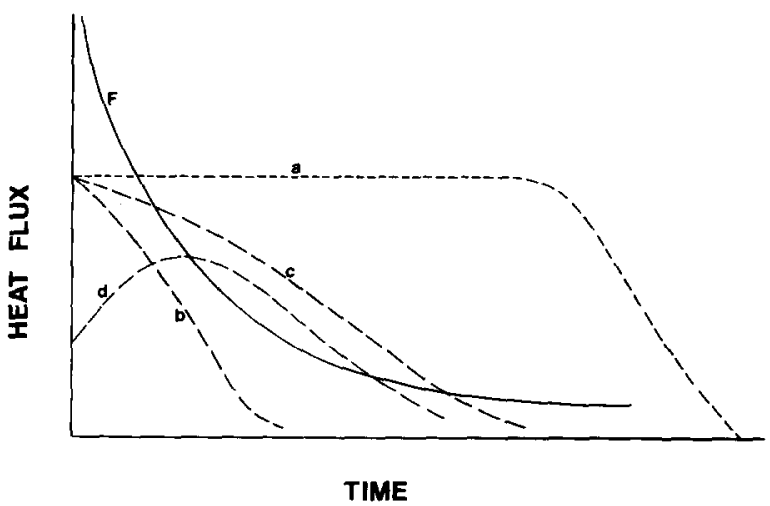

Fig. 1. Generalised variations of heat flux, $H$, in the fluid (dashed curves) and conductive flux in the solid, $F$ (solid line) with time. The various cases of variation of fluid heat flux are discussed in the text.

constant, there will come a time when $H$ exceeds $F$ (as depicted in the sketch of $H$ and $F$ in Fig. 1). From then on melting at the interface occurs. The previously solidified chilled margin will remelt, followed by the surrounding solid, provided that its melting temperature is equal to or less than the temperature of the fluid.

Consider a one-dimensional co-ordinate system with the $x$-axis pointing into the fluid normal to the initial planar boundary, with $x=0$ at the initial position of the boundary. (Note that with this convention the initial solid occupies negative values of $x$.) Then the governing equations and boundary conditions are:

$$
\begin{array}{ll}
T_{\mathrm{t}}=\kappa T_{x x} & {[x<a(t)]} \\
T=T_{\mathrm{f}} & {[x=a(t)]} \\
\rho L \dot{a}=-H+k T_{x} & {[x=a(t)]} \\
T \rightarrow T_{0} & {[x \rightarrow-\infty]} \\
T=T_{0} & {[t=0, x<0],}
\end{array}
$$

where $a$ is the thickness of the chilled margin, $\kappa$ is the thermal diffusivity of the solid, $\rho$ is the density of the fluid, $L$ is the heat of fusion, $k$ is the thermal conductivity of the solid and $t$ is time. For simplicity, we shall assume that the physical properties of fluid and solid are identical.

It is convenient to introduce the non-dimensional variables $\theta, \tau$ and $\xi$ into (2) to (6) defined by:

$$
\begin{aligned}
& T=T_{0}+\left(T_{\mathrm{f}}-T_{0}\right) \theta \\
& x=k\left(T_{\mathrm{f}}-T_{0}\right) \xi / H
\end{aligned}
$$


$t=\frac{1}{4} k^{2}\left(T_{\mathrm{f}}-T_{0}\right)^{2} \tau / \kappa H^{2}$

$a=k\left(T_{\mathrm{f}}-T_{0}\right) \eta / H$.

The system can then be described in terms of one parameter, known as the Stefan number:

$S=L / c\left(T_{\mathrm{f}}-T_{0}\right)$,

where $c$ is the specific heat of both fluid and solid. Physically, the Stefan number represents the ratio of the latent heat of melting to the heat needed to raise the solid from its initial temperature to its melting temperature. From equation (9) we can immediately deduce a timescale of the system as:

$4 \kappa H^{2} / k^{2}\left(T_{\mathrm{f}}-T_{0}\right)^{2}$.

At this time $H \approx F\left(=k T_{x}\right)$, and thus this timescale represents the point at which solidification of the chilled margin ceases and it begins to melt back.

Substitution of the non-dimensional parameters (7) to (11) into (2) to (6) leads to:

$$
\begin{array}{ll}
\theta_{\tau}=\frac{1}{4} \theta_{\xi \xi} & {[\xi<\eta(\tau)]} \\
\theta=1 & {[\xi=\eta(\tau)]} \\
4 S \dot{\eta}=-1+\theta_{\xi} & {[\xi=\eta(\tau)]} \\
\theta \rightarrow 0 & (\xi \rightarrow-\infty) \\
\theta=0 & (\tau=0, \xi<0) .
\end{array}
$$

These equations are nonlinear through equation (14) because $\eta$ represents the position of the unknown moving boundary, which moves due to

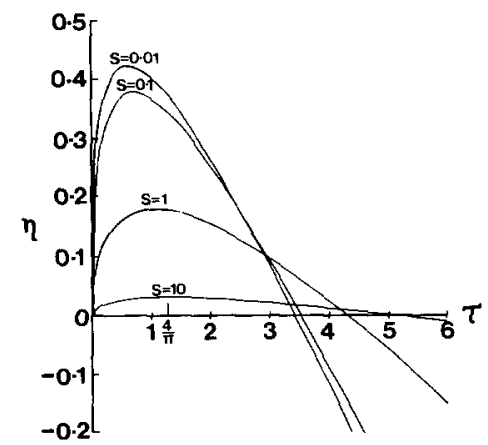

Fig. 2. Variation of non-dimensional chill thickness, $\eta$, against non-dimensional time, $\tau$, for four different values of the Stefan number, $S$. either the growth or melting back of the chilled margin. The equations have been solved numerically as detailed by Huppert [9].

Fig. 2 presents graphs of $\eta(\tau)$ for four values of $S$. The solutions all show that the chill grows with time and reaches a maximum thickness before melting back. The times taken to reach the maximum and then to melt back completely $(\eta=$ $0)$ are somewhat dependent on the Stefan number. The maximum thickness of the chill $\left(\eta_{\max }\right)$ decreases substantially with increasing Stefan number, reflecting the role of latent heat in inhibiting both the growth of the chill and its subsequent ablation.

These results are for a constant value of heat flux from the fluid (the horizontal portion of curve $a$ in Fig. 1). This assumption is reasonable for some situations, such as the steady flow of magma through a dyke, or flow of lava across the ground. However, there are other situations where $H$ can be expected to decrease with time. For example, in a sill of convecting magma there is a finite reservoir of hot fluid which cools with time. The temperature difference across the convecting magma layer, its Rayleigh number and hence the heat flow will decrease with time. In qualitative terms, two kinds of behaviour are possible. If the heat flux decreases sufficiently fast (curve $b$ in Fig. 1), the chilled margin will always grow because heat is removed faster by conduction in the solid than it can be supplied by the fluid to the interface. However, the heat flux may follow a curve (curve $c$ in Fig. 1) that intersects the conductive flux curve twice. At the second intersection, the solidified margin will begin to grow again. If the second intersection is at a time when the original chilled margin has not been completely remelted, a second internal contact will be formed between the first and second generation chilled margin. Another possibility for forming such an internal contact is shown in curve $a$ (Fig. 1), where after a finite time of constant heat flux there is a quite sudden decrease. This might happen if a lava ceased flowing rather abruptly due to its being ponded, for example.

There are numerous possibilities for different variations of heat flux with time and each must be treated independently and explicitly to ascertain whether meltback occurs and to what extent. Below we consider two examples. 


\section{Geological applications}

\subsection{Turbulent lavas and flow in dykes}

We have previously modelled the heat transfers that occur when a turbulent flow of lava moves across the ground [1,2] or ascends through a dyke $[2,3]$. We proposed that both the ground underlying the lava and the wallrocks of the dyke can melt and can be assimilated into the flowing magma. In the case of komatiites, we postulated that large thermal erosion channels formed and that nickel sulphide ores were generated by assimilation of sulphur-rich sediment [2]. Turbulent magmas could also assimilate crust by a similar process during ascent in dykes [3]. Claoué-Long and Nesbitt [12] questioned the efficacy of the thermal erosion, suggesting that the formation of a chilled margin forms an effective insulating layer between the ground and the overlying hot, turbulent lava. Huppert et al. [13] responded that they believed that any initial chill would rapidly dissolve again. The analysis in this paper gives an opportunity to assess the role of the chill in inhibiting thermal erosion.

The appropriate Stefan number for a komatiite laval flowing over cold ground is approximately 0.5 . As is apparent from Fig. 2, the timescales are weakly dependent on the exact value of the Stefan number. The maximum thickness of the chilled margin occurs for $S=0.5$ at approximately $\tau=0.8$ and $\eta=0.3$ [9]. In the following calculations, we assume that there is a steady turbulent flow of komatiite over the ground at a temperature of $0^{\circ} \mathrm{C}$. The heat transfer relationship (equation (1)) has the approximate empirical form [1]:

$H=0.02 \frac{k}{h} \operatorname{Pr}^{0.4} \operatorname{Re}^{0.8}\left(T_{\infty}-T_{\mathrm{f}}\right)$,

where $h$ is the flow thickness, $\operatorname{Pr}$ is the Prandtl number and $R e$ is the Reynolds number. Table 1 partially reproduces the results of calculations presented by Huppert et al. [1] in addition to calculations of the time for the chilled margin to reach its maximum thickness, $t_{\max }$, the time for the chilled margin to dissolve away, $t_{\mathrm{d}}$, and the maximum thickness of the chilled margin, $a_{\max }$. These values are calculated using equations (9), (10) and (17) and the results given in Fig. 2. For consistency, we adopt the same values of the physical parameters used in Huppert et al. [1]. Results are shown for temperature contrasts of $400^{\circ}$, and $40^{\circ} \mathrm{C}$ between the interior of the lava and the effective solidification temperature of the chill (taken to be $1200^{\circ} \mathrm{C}$ for komatiite). The results show that for $T_{\infty}-T_{\mathrm{f}}$ $=400^{\circ} \mathrm{C}$ the chill survives for typically a matter of a few tens of seconds and only attains a thickness of about a millimetre. If the temperature contrast is much lower, as will happen as the flow cools downstream, the survival of time of the chill increases to half an hour for $\left(T_{\infty}-T_{\mathrm{f}}\right)=40^{\circ} \mathrm{C}$. These calculations have not attempted to incorporate the effects of variable viscosity with cooling and in practice the survival time of chills will be further increased as the temperature difference $\left(T_{\infty}-T_{\mathrm{f}}\right)$ decreases further. The calculations confirm the view that initial chills can be rapidly dissolved and need not therefore have a significant influence on thermal erosion. The same results and conclusions apply equally to turbulent ascent of magma in dykes. As we noted in our previous work on komatiite flows [1,2], equation (17) is an empirical formula which has not been fully validated for fluids of high Prandtl number. While there are reasons to suppose that the heat transfer would be well approximated by the use of (17), the results obtained should be viewed as an indication of the probable magnitudes.

We stress, however, that if the flow becomes laminar as the lava either slows down or cools and increases in viscosity, then the heat flux from the interior will decline rapidly and the relationship between flow rate and heat flux will be entirely different to that given by equation (17). For a laminar flow the survival time of the chill will be much longer and the maximum thickness of the chill will be much greater. An analysis of heat transfer during laminar flow in dykes has been completed by one of our students, P.M. Bruce, who shows that if the dyke is sufficiently wide, and the flow continues for a sufficiently long time, the chilled margin can eventually melt back completely.

Finally, we emphasise that if the flow ceases quite suddenly, for example by becoming ponded, a new chilled margin or crust can once again form. Thus a fine-grained margin can be preserved, but it need not necessarily be the initial chill and its grain size will depend on the extent to which the underlying country rock has already been heated. 
TABLE 1

The lava flow thickness, $h$, its velocity, $u$, the heat transfer to the ground, $H$, the time of maximum chill thickness, $t_{\max }$, the time to dissolve the chill, $t_{\mathrm{d}}$, and the maximum chill thickness, $a_{\max }$, as functions of the two-dimensional volume flow rate $Q$ for a komatiite flowing over ground. The first four lines are for komatiite lava $400^{\circ} \mathrm{C}$ above the effective solidification temperature and final line for $40^{\circ} \mathrm{C}$

\begin{tabular}{lllllll}
\hline$Q\left(\mathrm{~m}^{2} \mathrm{~s}^{-1}\right)$ & $h(\mathrm{~m})$ & $u\left(\mathrm{~m} \mathrm{~s}^{-1}\right)$ & $H\left(\mathrm{~W} \mathrm{~m}^{-2}\right)$ & $t_{\max }(\mathrm{s})$ & $t_{\mathrm{d}}(\mathrm{s})$ & $a_{\max }(\mathrm{cm})$ \\
\hline 0.5 & 0.27 & 1.8 & $1.99 \times 10^{5}$ & 16.5 & 51.8 & 0.18 \\
1.0 & 0.43 & 2.3 & $2.17 \times 10^{5}$ & 13.9 & 43.7 & 0.16 \\
10 & 1.99 & 5.0 & $2.95 \times 10^{5}$ & 7.5 & 23.5 & 0.12 \\
$100(\Delta T=400)$ & 9.26 & 10.8 & $4.0 \times 10^{5}$ & 4.1 & 12.8 & 0.09 \\
$100(\Delta T=40)$ & 9.26 & 10.8 & $4.0 \times 10^{4}$ & $4 \times 10^{2}$ & $1.25 \times 10^{3}$ & 0.9 \\
& & & & $(0.5$ hour $)$ & \\
\hline
\end{tabular}

\subsection{Intrusive contacts}

When magma is intruded into a sill, a chilled margin will form for the same reasons as given in section 2. However, the theoretical analysis developed for the simple case of instantaneous influx of a hot fluid layer cannot be applied directly to an intrusion, because magmatic emplacement takes a substantial period of time in comparison with the evolution of the marginal chill. In the case of a sill of basalt that convects turbulently, the heat flux is given by the following form of equation (1):

$H=\rho c J\left(T_{\infty}-T_{\mathrm{f}}\right)^{4 / 3}$,

where:

$J=0.1\left(\rho g \kappa^{2} / \nu\right)^{1 / 3}$

and $\nu$ is the kinematic viscosity. This relationship is appropriate for high Rayleigh number convection $\left(R a>10^{6}\right)$. Martin et al. [14] and Carrigan [15] have convincingly shown that the Rayleigh numbers are typically well in excess of this value in magmatic intrusions provided that the magma is behaving as a simple Newtonian fluid. For basaltic magma with $\nu=185 \mathrm{~cm}^{2} \mathrm{~s}^{-1}$ and $T_{\infty}-T_{\mathrm{f}}$ $=10^{\circ} \mathrm{C}$ the heat fluxes are of order $3 \times 10^{4} \mathrm{~W}$ $\mathrm{m}^{-2}$ and so the chill should have a lifetime of only a few minutes. There are, however, several factors which need further consideration. First, it is not reasonable to suppose that magma can be intruded instantly and that convection can be initiated immediately. Second, there may be factors which inhibit convection and result in a substantially lower heat flux than given by [18]. For example, crystal-rich magmas may show markedly non-Newtonian behaviour and there is little information about convective heat fluxes in such sys- tems. In addition, crystals and bubbles in magmas may be distributed so that they create stable density gradients which counteract any unstable temperature gradients.

The thickness of the initial chilled margin will also depend on the time it takes to develop convection. Equation (18) represents an average heat flux at the roof taken over a time which is long compared with the characteristic time for instability of the thermal boundary layer. The equation is thus only relevant over an extended time scale and may not assess the initial chilling response quantitatively. Using the approach of Brandeis and Jaupart [16] for example, it is evident that the time scale for convective instabilities to develop might be of order $10^{2} \mathrm{~s}$ or longer so that a chilled margin at least a few tens of centimetres thick could form in that time. The controls on the rate of emplacement are neither constant nor well known. While it is clear that the initial thickness of the chilled margin will depend on the rate at which magma is intruded, a complete analysis of the problem would require modelling the deformation of the surrounding rocks as magma is emplaced, which is beyond the scope of both this work and current knowledge. Thus we can only surmise that the range of emplacement times and initial chill thicknesses will be quite large. The actual variation of heat flux out of a growing intrusion will follow some general path, as depicted by curve $d$ in Fig. 1 in which the heat flux increases with time as the intrusion increases in thickness and convection is initiated. The initial chill can then melt back when the convective heat flux into the chill exceeds the conductive flux through it. With time convection wanes, and the 
heat flux will once again decline to less than the conductive flux.

This situation can be analysed by the model of melting a roof presented by Huppert and Sparks [4] and using equation (18) to calculate the convective heat flux. We present calculations for a basaltic sill assuming an initial temperature of $1200^{\circ} \mathrm{C}$ and a chill with an effective solidification temperature of $1150^{\circ} \mathrm{C}$ so that initially $T_{\infty}-T_{\mathrm{f}}=$ $50^{\circ} \mathrm{C}$. The effective solidification temperature is taken as the temperature at which the magma achieves $65 \%$ crystallinity. The basaltic sill is assumed to have been emplaced sufficiently slowly that a substantial chilled margin forms next to the roof and that convection is then initiated within the fluid interior. We have calculated the rate of melting of the chilled margin at the roof and also the temperature variation of the convecting interior of the sill with time. Calculations are presented for thicknesses of the convecting interior ranging from 10 to $1000 \mathrm{~m}$. Again we emphasise that equations (18) and (19) are appropriate for a Newtonian fluid of constant viscosity and may not be appropriate for crystal-rich or bubble-rich magmas. Departures from the predicted heat transfer using these equations may arise in magmas due to temperature-dependent effects, kinetic effects in the nucleation and growth of crystals and non-Newtonian rheological properties. We have not attempted here to incorporate these effects as, although the quantitative results would change, the general principles are unaltered.

The melting rate depends on the initial temperature of the chilled margin [4], so calculations were made for $1000^{\circ} \mathrm{C}, 600^{\circ} \mathrm{C}$ and $0^{\circ} \mathrm{C}$. In de-

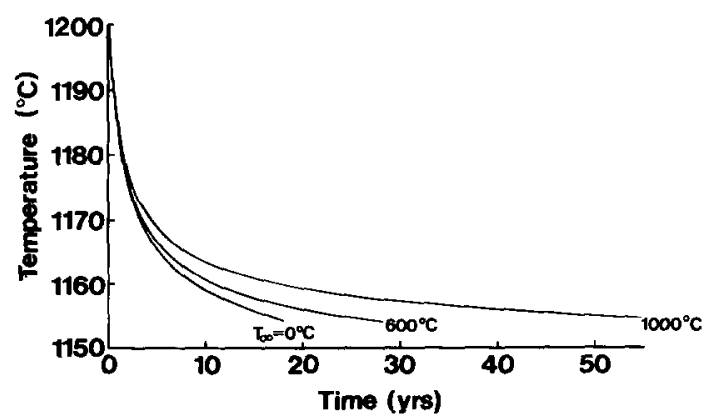

Fig. 3. Temperature variation with time in a convecting basalt layer with an initial thickness of $100 \mathrm{~m}$. Results are shown for three different values of the temperature of the solid roof (the chilled margin). tail, an initial chilled margin should be still quite warm, with its temperature varying from the solidification temperature to approximately the mean of the far-field country rock temperature and basalt temperature at the actual intrusive contact. Thus the calculations for $1000^{\circ} \mathrm{C}$ and $600^{\circ} \mathrm{C}$ represent a reasonable range of values for remelting a hot, chilled margin. The $0^{\circ} \mathrm{C}$ case is included because it would be relevant to a multiple intrusion where new magma is emplaced into the interior of a sill which has cooled down substantially. We assume that the remelted chill is mixed convectively back into the fluid interior. Consequently, the convecting interior increases in thickness and cools. The variation of viscosity is given by:

$\mu=\mu_{0}(1-1.67 x)^{-2.5}$,

where $\mu_{0}=30 \mathrm{~Pa} s$ is the viscosity at $1200^{\circ} \mathrm{C}$ and $x$ is the fraction of crystals, which varies linearly between 0 at $1200^{\circ} \mathrm{C}$ and 0.65 at $1150^{\circ} \mathrm{C}$. Further details of the theory and calculations can be found in Huppert and Sparks [4,5].

Fig. 3 shows typical results for the case of a 100 $\mathrm{m}$ convecting layer in terms of the temperature of the interior. The temperature decreases rapidly at first and then asymptotes towards the temperature of $1150^{\circ} \mathrm{C}$ as crystal content and viscosity increase and convective vigour diminishes. A convenient measure of the timescale of cooling is the time at which the Rayleigh number decreases to $10^{6}$, below which value equation (18) is no longer valid. Fig. 4 shows this time plotted as a function of the thickness of the convecting basalt layer and demonstrates that sills in the thickness range of 10 to $1000 \mathrm{~m}$ will approach solidification after times of a few years to a few tens of years. In all cases, the crystal content of the layer will be close to $60 \%$ at this time. Similar results were obtained by Huppert and Sparks [4] for melting country rock rather than a chilled margin.

Fig. 5 shows the thickness of the convecting layer as a function of time for an initial thickness of $100 \mathrm{~m}$. For each temperature the layer first increases in thickness with time, reaches a maximum and then decreases once again. Physically, these variations correspond to the chill first melting back and then renewed solidification beginning at the maximum where the condition $H=F$ holds. The results confirm that the initial tempera- 


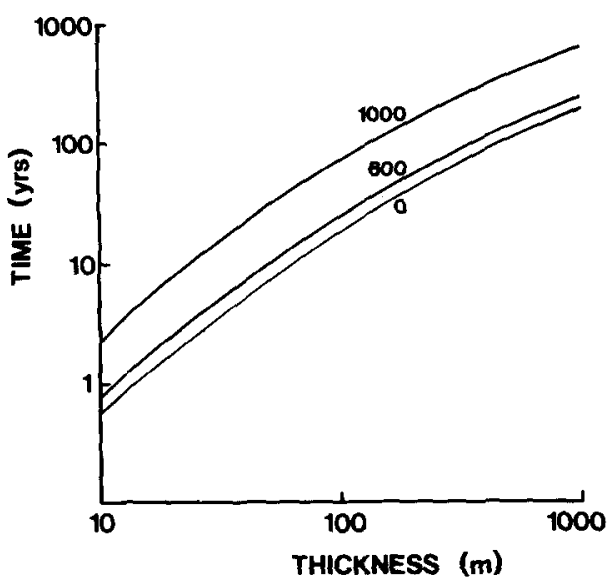

Fig. 4. Time taken for the Rayleigh number to decrease to $10^{6}$ is plotted against initial thickness of a convecting layer of basalt for initial temperatures of the surrounding country rock of $0^{\circ}, 600^{\circ}$ and $1000^{\circ} \mathrm{C}$.

ture of the chill plays a major role. If the chilled margin is hot, substantial meltback occurs, whereas only limited meltback can occur if the temperature is low. These results are specifically for a basaltic magma emplaced at its liquidus. For other kinds of magmas, the temperature differences driving convection and the melt viscosity may differ greatly from the values used here and would play an important role because of their influence on convective heat transfers.

The maximum in the thickness of the convecting layer allows an assessment to be made as to whether a chilled margin can be completely melted back. For the case of $T_{f}=600^{\circ} \mathrm{C}$ and thickness of

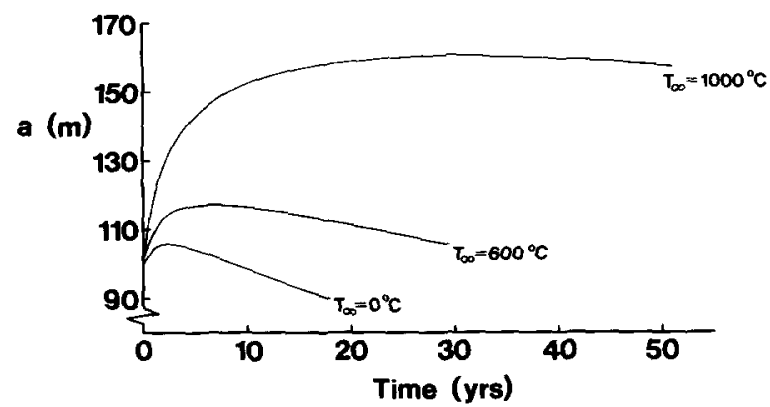

Fig. 5. Thickness of a convecting basaltic layer as a function of time for an initial thickness of $100 \mathrm{~m}$. Curves for three different temperatures of the solid roof (chilled margin) are shown. The convecting layer first increases in thickness as the chilled margin melts and then decreases as a solid crust grows again at the roof. The maximum corresponds to $F=H$.
TABLE 2

The maximum thickness (in metres) of chilled margin that can be remelted for different initial thicknesses of turbulently convecting basaltic sills and different initial temperatures of the solid roof (or chilled margin)

\begin{tabular}{rrcc}
\hline & $T_{0}=0^{\circ} \mathrm{C}$ & $T_{0}=600^{\circ} \mathrm{C}$ & $T_{0}=1000^{\circ} \mathrm{C}$ \\
\hline $10 \mathrm{~m}$ & 0.1 & 0.7 & 4.0 \\
$30 \mathrm{~m}$ & 1.0 & 3.5 & 15.4 \\
$100 \mathrm{~m}$ & 5.7 & 17.2 & 61.3 \\
$300 \mathrm{~m}$ & 25.9 & 64.8 & 174.0 \\
$1000 \mathrm{~m}$ & 115.6 & 260.7 & 586.4 \\
\hline
\end{tabular}

$100 \mathrm{~m}$, a roof-chilled margin less than $17 \mathrm{~m}$ thick would be completely melted back, whereas for a margin greater than $17 \mathrm{~m}$ thick, a new margin would begin to solidify, preserving a remnant of the initial chill above. Table 2 gives results for the maximum chilled margin thickness that can be completely melted back for different initial thicknesses of the convecting layer and temperature assumptions. The results suggest that the initial chilled margin has typically to be a few metres or tens of metres to prevent being remelted. For a sill of only $10 \mathrm{~m}$ thick, however, the amount remelted is limited to only a few tens of centimetres at most.

As discussed in section 2, we propose three kinds of intrusive contact depending on the integrated thermal history during emplacement and cooling of the magma (Fig. 1). The first kind of contact occurs if the heat flux out of the magma never exceeds the conductive flux. The initial chilled margin will then be preserved and, as is often observed, the grain size will gradually increase away from the contact.

The second kind of contact occurs when the outward heat flux comes to exceed the conductive flux. The chill can then be melted back, but will still be preserved because the outward heat flux drops below the conductive flux again before complete melt back has been accomplished, as illustrated by calculations for melting at the roof of a sill. An internal igneous contact should be preserved. The nature of this contact can be deduced from qualitative consideration of the cooling rate experienced at this position. The conductive heat flux monotonically decreases with time. The eventual position of the internal contact would have experienced a relatively fast cooling rate at the 
time of the growth of the initial chilled margin. However, following meltback, the cooling rate at the time when the second internal contact begins would be much slower. Consequently, the grain size would be expected to be considerably coarser and the internal contact would be associated with a slight increase in grain size. The initial chilled margin would be expected to become progressively partially molten during the remelting process, so that resorbtional textures might be anticipated. Thus in reality the internal contact might be gradational rather than abrupt. If the composition of the magma changes during the period of meltback, as might result from progressive emplacement of a zoned magma or internal differentiation, the internal contact would also be marked by a compositional break.

Internal contacts like these have been reported. In the Rosses Complex of Donegal, the main granite contains a marginal facies of fine-grained rock which ranges from zero to a few metres thick. It is cut by coarser-grained granite in the interior which increases in grain size inward. Internal contacts have also been observed in dykes and sills. For example, Henderson and Gibb [17] describe internal fine-grained margins towards the margins of the Lugar Sill in Southwest Scotland. Such contacts could be interpreted as evidence of multiple pulses. Our analysis shows, however, that internal contacts are still possible during a single intrusive episode. In the case of sills, the amount of remelting should be highly asymmetric. Heat flux is high at the roof owing to the convection. However, there is no convective flux to the floor so there should be no remelting. The chilled margin will be preserved and continue to grow at the floor. Remelting of the floor chill, however, could occur by flow through of magma in which heat is advected to both boundaries. Sills should, in principle, show a thicker basal contact chill than that preserved at the roof. Asymmetry has been observed in the Lugar Sill [17] in which a central intrusive unit has fine-grained contact with an upper outer unit and a much coarser lower contact with a thicker basal unit. Henderson and Gibb [17] noted that the substantial difference in grain size between these upper and lower contacts was puzzling. Such asymmetric features would be expected if the roof chill were selectively remelting by in situ convection followed by emplacement, although the asymmetry could be due to other factors such as kinetic effects related to different cooling rates at the roof and floor.

The third kind of contact occurs if the initial chilled margin is entirely remelted. Qualitatively we would expect this to occur in either large or hot intrusions where there is a large convective flux available for extensive periods, or where the magma is intruded rapidly so that only a thin initial chilled margin forms before meltback conditions arise. In this situation, the rock formed at the margin after meltback develops when the conductive thermal profile will have matured. Thus the chilled margin that forms eventually will not be as fine grained. This appears to be consistent with observations on marginal rocks from layered intrusions and large plutons [18]. In a large magma body, the country rock may also have melted back for substantial periods of time [4] so the conductive heat fluxes can become low by the time the magma begins to solidify once again. The marginal facies need not necessarily be fine grained because the cooling rates have become so slow. One would anticipate variations from inward coarsening to little change in grain size for the largest bodies. In some situations, for example, where the country rocks are refractory and do not melt, crystallization may occur directly against the wall to produce coarse-grained cumulative marginal rocks with no indication of a chill. We suggest that melting back explains why many large intrusions such as the Rhum ultrabasic complex, the Black Cullins of Skye and numerous others referenced in [18] and [19] do not preserve a finegrained marginal chill.

\section{Conclusions}

Contact of magma with cold rocks results in immediate formation of a fine-grained chilled margin. However, the chilled margin does not necessarily grow continually but can be partially remelted and even completely destroyed. Growth and remelting of a chilled margin depends on the thermal history of the magma expressed in terms of the time history of the imbalance between the conductive heat flux in the country rock and the heat flux from the magma induced by flow or convection. Meltback can be complete if flow is prolonged (for example, in a dyke or lava), or the 
convecting intrusion has sufficient internal heat. Initial chilled margins need not provide a barrier to melting and assimilation of country rocks. These concepts also suggest that the marginal facies of intrusions do not necessarily preserve the initial chill, but can form after prolonged meltback or assimilation of surrounding rocks.

\section{Acknowledgements}

We are grateful to Joyce Wheeler, who helped in carrying out the numerical calculations, and to Mark Hallworth, who helped draft the figures. An earlier draft of this manuscript was improved by comments from I.H. Campbell, F.G.F. Gibb, C.M.B. Henderson, C. Jaupart, R.C. Kerr, A.R. McBirney and M.G. Worster. Our research is supported by the BP Venture Research Unit and the Natural Environment Research Council.

\section{References}

1 H.E. Huppert, R.S.J. Sparks, J.S. Turner and N.T. Arndt, Emplacement and cooling of komatiite lavas, Nature 309 , 19-22, 1984.

2 H.E. Huppert and R.S.J. Sparks, Komatiites, I. Eruption and Flow, J. Petrol. 26, 694-725, 1985.

3 H.E. Huppert and R.S.J. Sparks, Cooling and contamination of mafic and ultramafic magmas during ascent through continental crust, Earth Planet. Sci. Lett. 74, 371-386, 1985.

4 H.E. Huppert and R.S.J. Sparks, The generation of granitic magmas by intrusion of basalt into continental crust, $J$. Petrol. 29, 599-624, 1988.

5 H.E. Huppert and R.S.J. Sparks, Melting the roof of a chamber containing a hot turbulently convecting fluid, $J$. Fluid Mech. 188, 107-131, 1988.
6 A.R. McBirney, B.H. Baker and R.H. Nilson, Liquid fractionation, I. Basic principles and experimental simulations, J. Volcanol. Geothermal Res. 24, 1-24, 1985.

7 R.H. Nilson, A.R. McBirney and B.H. Baker, Liquid fractionation, II. Fluid dynamics and quantitative implications for magmatic systems, J. Volcanol. Geothermal Res. 24, 25-54, 1985 .

8 I.H. Campbell and J.S. Turner, A laboratory investigation of assimilation at the top of a basaltic magma chamber, J. Geol. 95, 155-173, 1987.

9 H.E. Huppert, Phase changes following the initiation of a hot turbulent flow over a cold solid surface, J. Fluid Mech. 198, 293-319, 1989.

10 T.L. Wright and R. Okamura, Cooling and crystallization of tholeiitic basalt, 1965 Makaopuhi lava lake, Hawaii, U.S. Geol. Surv. Prof. Pap. 1004, 1-78, 1977.

11 H.R. Shaw, The fracture mechanisms of magma transport from the mantle to the surface, in "Physics of Magmatic Processes", R.B. Hargreaves, ed., Chapter 6, pp. 201-264, Princeton University Press, Princeton, N.J., 1980.

12 J.C. Claoué-Long and R.W. Nesbitt, Contaminated komatiites: a discussion, Nature 313, 247-248, 1985.

13 H.E. Huppert, R.S.J. Sparks and N.T. Arndt, Contaminated komatiites: a reply, Nature 313, 247-248, 1985.

14 D. Martin, R.W. Griffiths and I.H. Campbell, Compositional and thermal convection in magma chambers, Contrib. Mineral. Petrol. 96, 465-475, 1987.

15 C.R. Carrigan, The magmatic Rayleigh number and time dependent convection in cooling lava lakes, Geophys. Res. Lett. 14, 915-918, 1987.

$16 \mathrm{G}$. Brandeis and C. Jaupart, On the interaction between convection and crystallization in cooling magma chambers, Earth Planet. Sci. Lett. 77, 345-361, 1986.

17 C.M.B. Henderson and F.G.F. Gibb, The petrology of the Lugar Sill, SW Scotland, Trans. R. Soc. Edinburgh 77, 325-347, 1987.

18 L.R. Wager and G.M. Brown, Layered Igneous Rocks, 588 pp., Oliver and Boyd, Edinburgh, 1968.

19 I. Parsons, Origins of Igneous Layering, Reidel, Dordrecht, 1987. 